\title{
On accidental double refraction
}

\section{J. Macé}

To cite this article: J. Macé (1877) On accidental double refraction, Philosophical Magazine Series 5, 3:21, 547-548, DOI: 10.1080/14786447708639285

To link to this article: http://dx.doi.org/10.1080/14786447708639285

曲 Published online: 27 Jul 2009.

Submit your article to this journal $\widetilde{ }$

Џ Article views: 2

Q View related articles $₫$ 
is continually changing its values, from the rest which remains constant. It is therefore likely that the classification of light into three kinds, according as the violet, the red, or the green is contained in the smallest proportion, is one which has a relation to the natural powers of discrimination.-Silliman's American Journal, A pril 1877.

ON ACCIDENTAL DOUBLE REFRACTION. BY J. MACÉ.

The phenomena of accidental double refraction produced by compression have, since their discovery by Browster, given rise to numerous researches, while those produced by tempering have bet $\mathbf{n}$ but little studied. Since the discovery of the latter by Seebeck, we find but little concerning them except the papers of $\dot{M}$. de Luynes, in which the author studies chiefly the mechanical properties acquired through an energetic tempering, and those of M. Mascart on the tempering of cast plates of glass (Journal de Physique, 1876), in which the author applies himself especially to the practical side of the question.

The aim of the investigation which I commenced some months since was, on the contrary, to discover what are the laws which govern this phenomenon, and to search out the analogies or the differences which might exist between that which results from tempering and the other cases of accidental double refraction. I therefore proposed to myself to study plates of simple geometrical forms, especially rectangular and square, differing in dimensions, thickness, and constitution. If it be remarked that Wertheim, by the study of the regular compression of glass, has been able to show that the differences in the course are proportional to the pressures exerted, it will ke seen that this led me to investigate the distribution of the differences of the course in the various plates submitted to experiment.

The arrangement employed was very simple :-A car carrying the plate permitted it to be displaced parallel to a micrometer formed, as in M. Jamin's apparatus, of two parallel fine threads and, besides, of a third, horizontal thread, rendered necessary by the curved form often (and particnlarly in square plates) affected by the fringes to be studied. As always, the polarizer was placed at $45^{\circ}$; the analyzer was alternately transverse and parallel, so as to exhibit fringes corresponding to differences of course varying by half wavelengths. The compensator was suppressed, it laving the inconvenience of deforming the fringes and often rendering them difficult to observe; but it was made use of for the rectangular plates, in order to measure the central difference of course. For the illumination the burner of Laurent's saccharimeter was used. The position of each fringe was measured to within 0.1 of a millimetre at the least.

In studying the distribution of the course-differences along a line parallel to and equally distant from two of the sides of the plate, the phenomenon could in all cases te represented by a formula 
identical with that representing the distribution of magnetism in a magnetized bar :--

$$
y=\mathrm{A}\left(\mathrm{K}^{x}+\mathrm{K}^{-x}\right),
$$

reckoning $x$ from the middle of the plate; or

$$
y=\mathrm{A}_{1}\left(\mathrm{~K}^{x}+\mathrm{K}^{2 l-x}\right),
$$

counting from the margin. The differences between calculation and observation were always less than the possible errors of observation, and only exceptionally rose to 0.01 of the measured Jength.

I will add that, in a long rectangular plate, for the distribution of the fringes parallel to the longer sides a curve was obtained similar to that of brachypolar magnets ; any square plate gives a similar curve to that of megapolar magnets. For example, there are found :-for.a rectangular plate, $A=2 \cdot 53, K=2 \cdot 99$; for a square plate, $A=0.0124, K=100.5$. The ordinate-unit is the balf of a wave-length; the unit of length, the centimetre.

After these researches the question naturally arose, Are these phenomena to be attributed, as Neumann thought, to a regular action exerted upon the glass mass by the outer layers at the time of its solidification? In regard to this I have made several series of experiments, varying the conditions ; but in all cases $I$ was conducted to the same conclusion : the causes of these two phenomena are completely different.

It is quite otherwise when the effects of tempering are compared with those resulting from regular heating of a plate of glass through its contour. Examining with the polarizing microscope a square plate of glass heated by the usual processes, one is struck with the similarity of the phenomena. Unfortunately, the rapidity with which the colorations change and disappear did not permit precise measurements to be made; I was therefore obliged to have recourse to an artifice.

I took two rectangular plates derived from the same plate of glass, and both having absolutely jdentical dimensions. One was feebly tempered; the other could be introduced into a hot metallic piece constructed specially for the purpose. It was at once perceived that the signs of a tempered and of a heated plate are the same. If, moreorer, after arranging upon the polarizing microscope the tempered plate at $45^{\circ}$ from the plane of polarization, the heated plate of the snme shape be superposed crossing it, a moment comes when the common part is traversed by a blark cross, the arms of which pass through the four vertices of the square of intersection. This phenomenon can only be produced if the distribution of the retardations is at that instant the same in both plates. Double refraction produced by tempering is therefore identical with that which is produced by a regular heating through the contour of the plate.-Comptes Rendus de l'Acctémie des Sciences, May 7, 1877, tome lxxxiv. pp. 1024-1026. 